\title{
Living The Dream In An Erudite World: Writing As If One's Career Depends On It
}

Michael Craig Budden, Southeastern Louisiana University, USA

\begin{abstract}
In academia, the old maxim, "publish or perish" sends chills down the back of many. Junior faculty members, especially, are rightfully concerned a lack of publications may inhibit their professional growth and, more importantly, their professional survival. Thus, for many, if not most, of those who pursue an academic life, publishing is a necessary and important part of the job. This article provides advice on beginning and maximizing writing and publishing efforts from an experienced editor and reviewer.
\end{abstract}

Keywords: Publishing, Writing, Tenure and Promotion, publications

\section{INTRODUCTION}

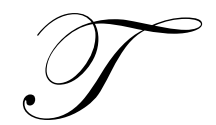

enure and promotion decisions often involve discussions as to the appropriateness, quantity and quality of a candidate's publications. Sure, teaching and service activities are considered, but generally they are less debated in the decision process as is publication viability. Publications are central to not only tenure and promotion decisions, but to annual assessments of performance.

A faculty member who leaves his/her publication activities to chance is naïve in thinking such a behavior will improve their chances of publishing success. Writing and submitting randomly with the hope of publication increases the risk of publication rejection and bodes poorly for the likelihood of one gaining sufficient publications to gain departmental approval. It appears many have an attitude that is something akin to if you write it, the publication will surely come. Sadly, they are often disappointed. A plan of action to increase one's chances of publication success is advisable. An aspiring author can do many things to improve his/her publication success and increase their chances of not only surviving, but living their dream in an erudite world.

\section{IMPACTS OF OTHERS}

Never underestimate the power of others. In beginning a career in which publishing will be a fundamental activity, it is important to find someone who is a successful colleague/writer and work with them. The term mentor may be overused, but making connections that lead to collaborative research and publishing efforts is important. The mentor may be a senior faculty member or a member of one's dissertation committee. Whoever one's mentor is or mentors are, mentors should have a record of publishing in the field, a willingness to work with others, and be capable of providing support for one's efforts.

In seeking the advice and help of mentors, one must be open to suggestion and criticism. The author is aware of a situation where a junior faculty member had a paper the faculty member considered to be of high quality. At the same time, the faculty member was under a time deadline to produce a journal publication needed for an approaching tenure and promotion decision. The mentor spent much time editing the paper and working to develop the paper for a particular publication. Before submission, the faculty member decided the final product was too good for the level of journal targeted, and against the advice of the mentor submitted the article to another journal. That journal received the paper and held it for almost a year before summarily rejecting it. The journal held it for a year - an important and unproductive year in a faculty member's drive for tenure. 
After receiving the rejection, the faculty member sent the article to the mentor's targeted journal. Within a relatively short period of time a letter was received accepting the article for publication pending minor revisions. A mentor had been insulted and the faculty member wasted a year waiting for a publication that would count as only one of several that would be needed to earn tenure. Help from others, especially those who are successful and in the field, can prove a significant advantage not just for junior faculty members, but for the experienced as well.

Closely related to working with a mentor is the realization that working with co-authors can be rewarding. The concept of synergy applies to the research and writing efforts of faculty members. Two faculty members working together can create more and hopefully better output than two working independently. Indeed, the amount of synergy arising from co-authoring can astound. New ideas, new procedures, new statistical processes are found in the knowledge of others and it is these ideas that provide the impetus for much good from developing research and publishing relationships with others. Be collegial. Work with others. Bringing together disparate fields to produce a publication works to the advantage of all. Co-authoring develops ties and networking opportunities and can pay dividends for years.

Developing contacts can be useful to one's career efforts. One should go to conferences. Once there, one should seek out and meet conference organizers, editors and authors who may prove beneficial in the future. Ask for advice on ways one can improve professional efforts. While speaking with editors, one should ask about needs of their journals or potential special issues being planned. With such knowledge, one may be able to target their efforts to satisfy the editor's needs. Meeting others with similar research interests may lead to collaborative efforts that will pay off.

Another effort leading to understanding and collaboration is to invite editors to speak to faculty in one's college in an effort to prepare all to better serve the needs of the editor's journal. For example, the author sponsored a panel of five journal editors to speak on his campus about publishing. The information shared by the editorial panel was enlightening and resulted in not just an increase in writing activity by many, but an improved hit rate.

\section{WRITE OFTEN AND WRITE WHAT YOU KNOW}

It is sage advice - writers should write every day. Regardless of the amount of writing done, write every day. Producing one page a day allows one to write a book and then some in a year. Surely, one page a day will result in numerous articles. The author is aware of a professor who holds an endowed chair at a major university who daily spends four hours (8a.m.-12noon) writing. He teaches his classes in the afternoon. The professor has produced hundreds of articles and numerous books. While few could imitate that record or spend that much time writing, one can and should develop the habit of writing regularly.

Similarly, one should write what one knows. "Write what you know" is advice found in many books and articles on the craft of writing. The author once had a faculty member proffer it was wrong to write more than one article on a subject! What could he be thinking? By conducting much research and writing in an area, one becomes an expert. An expert will be called upon to speak, to consult and to participate in other efforts leading to a better understanding of the subject. In addition, by writing multiple articles on one subject area, one already knows the literature. This will save time and prevent having to reinvent the wheel with each effort. Many authors are prolific because they find an area of study and exploit it to the max. It is not unusual to find prolific authors who write 15, 20,30, and even more, articles on a subject. The articles have different objectives, different information, different viewpoints, and perhaps different writing styles depending on the target publication. Another advantage of being well known in an area is one is more likely to receive invitations to submit an article - an easy way to improve productivity. Save time, save energy and produce more. Exploit a subject and become an expert.

\section{KNOWING THE JOURNAL}

Write for a particular publication. Writing for a particular publication means one has read the publication and one is familiar with not only its content, but its editorial slant and requirements. The number of times an article is submitted for review by an author who has never read the target journal is amazing. It can also be a waste of the author's time and, more importantly, the time of the reviewers and editor. If one hasn't read a journal one intends to 
submit to, one should save everyone a lot of time and energy and don't submit to it. If one doesn't subscribe to the journal, get the school's library to subscribe. Or one should go online, if the possibility exists, and read the journal. Read the journal and understand what the journal is seeking.

A journal recently received a paper for review printed in small font and yet the paper still numbered over 40 pages. For a journal that seldom has more than 75 pages in an issue, the odds of the editor sending out a 40 page paper for review are not good. Indeed, the odds of acceptance are something akin to the odds of the author winning the Powerball lottery. Perhaps the good news for such authors is the rejection will arrive quickly.

Related to the concept of knowing the publication is being aware of submission requirements, style sheets, and other requirements. Evidence an author does not know or has even read the journal can often be found in a paper's reference list. If the style of references (or footnotes) in a paper is not as expected or required, the paper almost screams out it was sent elsewhere, found lacking by others and summarily rejected. Having been found lacking and being rejected by others bodes poorly for a review by new editors and reviewers who will immediately note the paper does not meet their guidelines. This is not to say if something is rejected by one publication it should not be sent elsewhere - nothing is further from the truth. But before sending it elsewhere, be sure the article fits the new journal's style, audience and requirements.

One way of indicating one knows a journal is by citing the journal's articles in one's submission. Citing the journal in the paper indicates one knows the journal, its slant, its audience and its style. A parallel avenue is to cite the editor's work when appropriate. Members of the editorial panel mentioned previously agreed if an editor is an expert in the field, then it would stand to reason the editor's work would be cited in any relevant article. Still, a citation doesn't guarantee success, but the absence of such may indicate a lack of mastery of the subject.

Always include a cover letter with submissions. The letter can be short and sweet, but it is best if it helps sell your article. A cover letter should indicate why the article is appropriate for the journal and its reader. While a cover letter alone will not sell a poor article, it does not hurt for the editor to have a feel of the author's intent and logic. The cover letter should also include author contact information.

\section{KNOW WRITING / KNOW THE PAPER}

Sadly, writing skills development in many graduate programs leaves much to be desired. As a result, it is up to authors to assure clarity of thought. There are numerous magazines and books on writing - read some. Papers should be written in clear English. Grammar errors should be minimized or preferably, non-existent. Proofread papers before submitting. Preferably, have colleagues proofread the paper before submission. Be sure the paper meets style guidelines of the journal.

A disturbing trend noted by the author is the number of citation errors in some submissions. In a recent submission, a dozen citations in the paper were not found in the reference list. In addition, some 20 articles in the reference list were not cited in the paper. With glaring errors, the quality of the rest of the paper is suspect. A plus for the reviewer, with glaring errors among the citations, the need to consider the article for publication is moot, providing the reviewer time to consider other, more deserving articles. Errors and inconsistencies among references are easy to detect with digital submissions. Submitting a paper with glaring errors will almost certainly result in an unsatisfactory reply from the editor. Rejection can come quickly.

Be open to suggestions from an editor. If a paper receives a positive recommendation pending the addressing of some items, one should consider making those changes. And the quicker one makes the recommended changes, the better. It is to the author's advantage to keep the paper in the mind of the reviewers and editor. Recommended changes should only be accepted by the author when those changes improve the document and do not change the findings or objectives of the paper. If the author objects to a recommended change from a reviewer or editor, but still desires the publication, the author should respond in writing to the editor as to why such a change is unwarranted or presents problems. 
An article received by a journal was timely, exhibited a strong methodology and contained appropriate conclusions. The paper was well-written. The reviewers recommended acceptance pending 1) the removal of a paragraph impugning an article irrelevant to the current study, and 2) suggested a few minor editorial changes. The author resubmitted the paper including the editorial changes, but left the offending paragraph with no explanation. The paper was reviewed again and returned to the author with the original concern the paragraph was unsubstantiated and irrelevant. A recommendation the paragraph be removed or revamped to address the concerns of the reviewers was included. Surprisingly, the third submission retained the offending paragraph with no explanation. The third submission resulted in a curt letter from the editor stating if the author wished to see the paper published, he had to remove the paragraph or he should consider the letter notification the article was rejected. Shortly, a fourth version of the paper with the offending paragraph removed was received and subsequently the article was published. One should not accept editorial recommendations carte blanche, but absent a reason to the contrary, one needs to address editorial findings quickly and decisively. Editors serve a purpose. Listen to them.

Editors do more than edit. They can help. An editor called the author once about an article submitted for potential publication. The editor had checked a statistic included in a table and found an error. He also said he liked the paper and wanted to publish it. The error was corrected quickly, the paper resubmitted and subsequently published. The author had the opportunity to get to know the editor and found his philosophy was to help people get published - not to reject papers. Since then, the author has found other editors with similar philosophies. Faculty should be alert to finding such editors as they are a welcome presence in what can be a challenging environment. Find publications where the editor has a reputation for helping people get published and work with them.

\section{MISCELLANEOUS ADVICE}

Submit articles as directed. If the journal wants digital submissions only, then submit digitally. If a journal requires hard copies, then submit hard copies. If there is a submission deadline as there may be with a special issue, meet the deadline. Better yet, beat the deadline. Provide the paper in the correct font, style, and page constraints. These are small but important factors in the submission process.

Be realistic - aim high, but get what is needed. The author is aware of a faculty member at another university who had a tenure track line with publication expectations. For more than four years, the faculty member had no publication. As the goal of the faculty member was to publish only in top journals in his field, he had worked for years to perfect one particular article. During his last probationary year he did it. He had the article accepted in what was arguably a top journal in his field. A great publication success; but it was just a single publication. One publication was less than the expected number required to earn tenure. The faculty member is now employed elsewhere. Aim high but don't neglect that which is required.

Work on many projects. The best publishers typically juggle many papers at once. If something is rejected, send it to another potential journal - being sure to gear it to the needs and expectations of the new outlet before sending it forth. If the editor or reviewers included suggestions for improvement, consider them before proceeding. In any case work on several projects and keep sending articles out. Many new journals emerge every year. New journals especially are seeking articles contributing to knowledge in their field and which can help them become established. New journals offer a prime opportunity for those seeking publication.

\section{CONCLUSION}

One can live the dream in an erudite world. One needs to write much and write often. Having a mentor and/or co-authors can improve one's chances of being published as well as increase the number of publications. One needs to read and know the journals they target. One needs to consider the needs and expectations of potential outlets and editors. One needs to address recommendations of reviewers and editors, while maintaining research quality, findings and recommendations. One needs to submit well-written papers. Citations should be correct and the reference list should contain all citations. Aim high, but get the publications expected during the time allowed. Work on several projects and complete them early. Submit them in a timely manner. Do these and live the dream. 